\title{
Pollutants waft over the Himalayas
}

World's highest mountain range is no barrier to smoke from south Asia's cooking stoves and forest fires.

Jane Qiu

14 April 2015

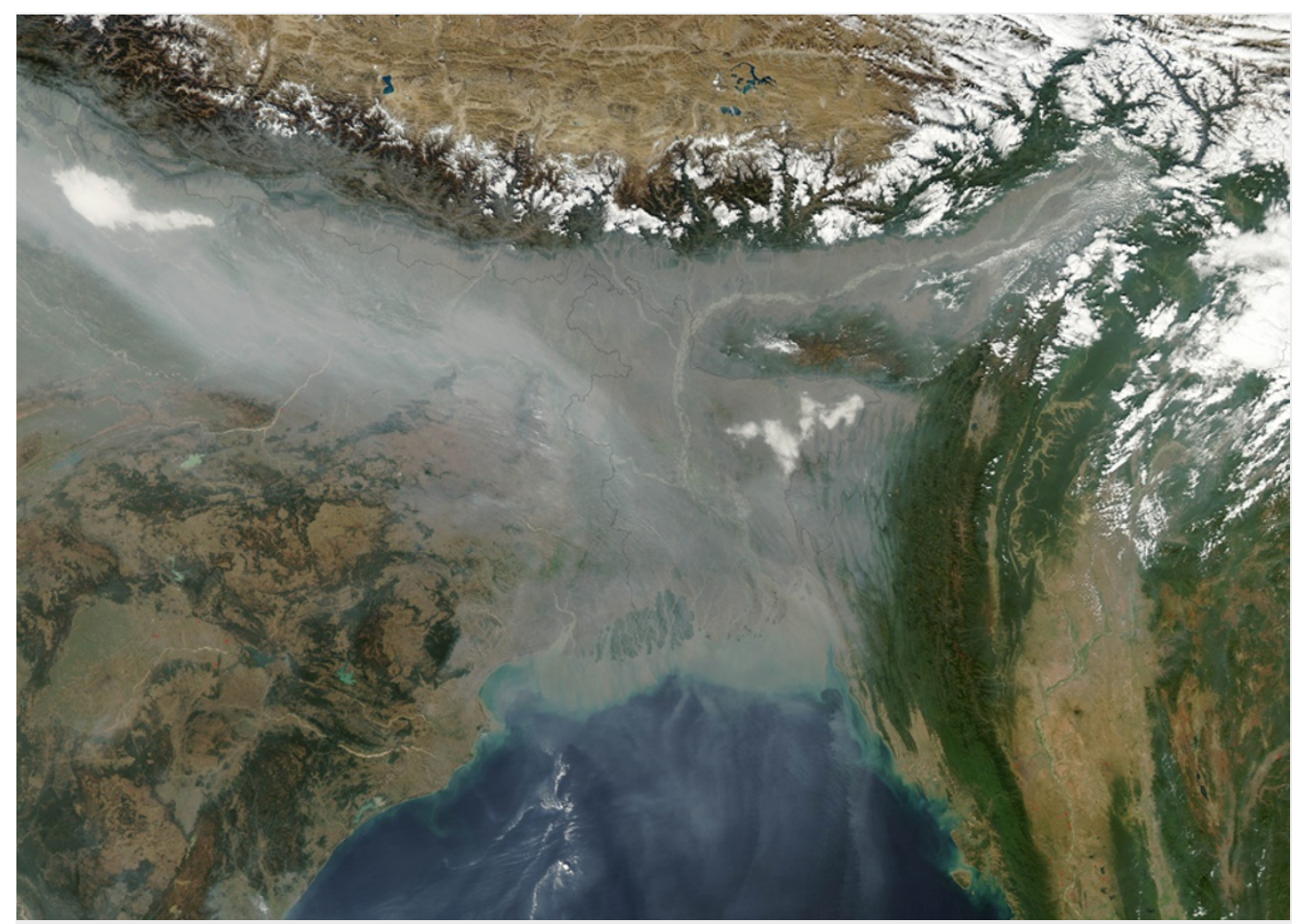

Jeff Schmaltz, LANCE MODIS Rapid Response/NASA

A satellite image (from the MODIS instrument on NASA's Aqua satellite) shows haze pollution hugging the Himalayas; new data suggests it can pass over the mountain range to reach the Tibetan Plateau further north.

Pollutants on the icy Tibetan Plateau, which absorb solar radiation and are accelerating the melting of snow and ice, are known to come from as far afield as Africa and Europe. But work by Chinese researchers now suggests a brownish haze of pollution from forest fires, crop burning and domestic cooking stoves in south Asia is also contributing to the problem. It can waft up and over the Himalayas to settle on the plateau, they report.

"Many people assume that pollutants piling up on the southern slope of the Himalayas would not go anywhere because the mountains are simply too high," says Cong Zhiyuan, an environmental scientist at the Chinese Academy of Sciences' Institute of Tibetan Plateau Research in Beijing.

There were indirect signs that pollution could travel over or around the mountain range: for example, ice-core samples taken from the southeastern Tibetan Plateau show rising soot concentrations during times of rapid industrial growth in India. In two studies — one published last week ${ }^{1}$, and one earlier this year ${ }^{2}$ — Cong and his colleagues report more definitive evidence that the Himalayas do not block pollution's passage from the south: they find similar types and concentrations of pollutants on both the south and north sides of Mount Everest.

The researchers do not know to what extent the trans-Himalayan pollutants contribute to the total load of soot and other carboncontaining combustion products dumped on the Tibetan Plateau. But south Asia's contribution has been a hotly debated issue, says Veerabhadran Ramanathan, an atmospheric scientist at the Scripps Institution of Oceanography in La Jolla, California. "This is a very important finding," he says.

Cong's team took weekly measurements from August 2009 to July 2010 at the Qomolangma (Mount Everest) Station for Atmospheric and Environmental Observation and Research, which sits 4,276 metres above sea level, on the northern slope of Everest. The 
researchers say that the concentrations and chemical components of pollutants were similar to those captured on the southern side of the mountain, at the Nepal Climate Observatory at Pyramid Station, 5,079 metres above sea level. Both stations are part of the global Aerosol Robotic Network (AERONET) of observatories, which allows for standardized pollution tracking.

\section{Biomass to blame}

The pollution included organic compounds and sulphate ions - signatures of burned biomass, such as from cooking stoves fed by wood or crops, or from forest fires. And pollutant levels were high at times when NASA satellites spotted forest fires or the burning of agricultural crops in south Asia.

Showing that pollution fingerprints are similar on both sides of the mountain is "a step forward", says Ramanathan — but he is not sure that the case for trans-Himalayan passage is conclusive. Pollutants might be blown from eastern China or come from biomass burning elsewhere on the plateau, he suggests.

Cong is more confident; he says that there is little biomass burning on the plateau and the prevailing winds tend to blow from the south and west, making a source in eastern China unlikely. His team also reports that whereas valley winds on the southern side of Everest blow upslope during the day, those on the northern side blow downwards. That combination is unusual (valley winds normally rise during the day and descend at night), and could be acting as a channel for south Asian pollutants, he says.

"Regardless of where the pollutants come from, the study has provided compelling evidence that they are due to biomass burning," says Ramanathan. "We must step up the global effort to drastically cut down biomass burning as much as we can."

Nature I doi:10.1038/nature.2015.17312

\section{References}

1. Cong, Z., Kawamura, K., Kang, K. \& Fu, P. Sci. Rep. http://dx.doi.org/10.1038/srep09580 (2015).

2. Cong, Z. et al. Atmos. Chem. Phys. http://dx.doi.org/10.5194/acp-15-1573-2015 (2015). 